\title{
Anthropo-Social Palliative Care to Dying Patients with Chronic Diseases: A Case Study of Centre Hospitalier Universitaire de Kigali (CHUK): 2015-2017
}

\author{
Father Dr. Lucien HAKIZIMANA*, NYIRAHIRWA Rose, UFITINEMA Berthilde \\ University of Technology and Arts of Byumba (UTAB), Rwanda
}

*Corresponding Author: Father Dr. Lucien HAKIZIMANA, University of Technology and Arts of Byumba (UTAB), Rwanda

\begin{abstract}
This research highlights how anthropo-social palliative care is providing quality of life to patients with chronic diseases at CHUK.

This research intended to answer to research questions in the line with achieving the following objectives: to identify problems of patients with chronic diseases at CHUK, to sort-out challenges of anthropo-social workers in providing palliative care in CHUK and to highlight the role of anthropo-social workers in providing palliative care in $\mathrm{CHUK}$.

This research to be successful, different methods and techniques were used. As methods we used analytical and descriptive methods. As techniques, we used the interview, questionnaire, observation and documentation. The data were collected and interpreted basing on quantitative and qualitative approaches.

As results of our research, concerning the problem of patients with chronic diseases; $44.25 \%$ of respondents confirmed emotional problems; $74.5 \%$ of respondents confirmed problem of daily life; $72 \%$ showed psychological problems; $80 \%$ of respondents confirmed economic problem while $73.4 \%$ confirmed anthroposocial problems.

About challenges of anthropo-social workers in providing palliative care in CHUK, $81 \%$ showed lack of experience, $90 \%$ demonstrated inadequate training, 32\% were with insufficient compensation, $46 \%$ of the respondents confirmed personal discomfort with death. Regarding the role of anthropo-social workers in providing palliative care in CHUK, 100\% confirmed psychosocial support, advocacy and care delivery, $88 \%$ confirmed the therapeutic intervention, $81 \%$ counseling.
\end{abstract}

Keywords: Palliative Care, Dying Patients, Chronic Diseases, Anthropo-social workers, CHUK, problems, challenges, pain

Abbreviations: CHUK: "Centre Hospitalier Universitaire de Kigali”, HIV: Human Immunodeficiency Virus, WHO: World Health Organization, AIDS: Acquired Immune Deficiency Syndrome

\section{INTRODUCTION}

Palliative care is essentially a response to patients and family members facing the diagnosis of lifethreatening diseases. Hospice patients face many problems, some of which require legal interventions. Legal issues can increase emotional stress in patients and families and impact on the way they cope with the diseases ${ }^{1}$

Living with chronic diseases is a big challenge. Patients and their loved ones need to find healthy and constructive responses to the stress of living with chronic diseases. According to the World Health Organization, palliative care is an approach that improves the quality of life of patients and their families facing the problems associated with life-threatening diseases, through the prevention and relief of suffering by means of early identification and impeccable assessment and treatment of pain and other problems: physical, psychosocial and spiritual ${ }^{2}$.

1 A. Daley, C. Matthews, A. Williams, (2006). Heart Failure and Palliative Care Services Working in Partnership: Report of a New Model of Care. Palliative Medicine, 20(6):593-601.

2 J. A. Smith, T. Greer, T. Sheets, S. Watson, (2011). Is there more to yoga than exercise? Alternative Therapy Health Medicine, 17 (3), 22-29. 
Demographic trends coupled with a rise in long-term health conditions and chronic diseases mean that the core population of patients requiring palliative care is people with chronic diseases. This is a particular challenge for palliative care whose demographic profile has tended to be younger and whose historic disease focus has predominantly been cancer ${ }^{3}$.

Every year, dozens of people with terminal illnesses are abandoned by their loved ones at CHUK. When terminal illness sets in, it takes a toll on the loved ones of the patient both financially and psychologically. Some are lucky to manage while others give up along the way when resources can no longer permit. So desperate family members literally abandon their loved ones in hospitals with hope that the hospital would offer help to people living with chronic cancer, diabetes, HIV, kidney diseases and other related ailments on top of the physical pain they suffer from psychological pain that requires social work intervention, mainly counseling ${ }^{4}$.

Patients who reach the end stage of advanced illness may also suffer from a variety of complications, including anorexia, weakness, and sexual dysfunction. Multiple interacting symptoms contribute to suffering (which is manifest by depression, cognitive disturbance, and interpersonal and spiritual crises) at the end of life. Furthermore, dying patients and their families often have to deal with complicated "practical" issues, such as financial problems (e.g., paying for home care) and legal issues (e.g., organizing wills or health care proxies). These seemingly mundane concerns can cause a great deal of distress for dying patients and their families ${ }^{5}$.

Despite that, the Ministry of Health and other stakeholders say they are working hard to train more palliative care professionals in the sector. At CHUK there is deficiency of social workers trained to help people living with chronic diseases as confirmed by Magnus Udahemuka Gasana, a Palliative Care Desk coordinator in October 2016 in The New Times ${ }^{6}$.

This gap concerning this field of study pushed us to showcase the role of anthropo-social workers in providing palliative care to patients living with chronic diseases in CHUK.

This research aimed at responding to the following crucial question: What is the role of anthroposocial workers in providing palliative care to patients living with chronic disease at CHUK?

To highlight the role of anthropo-social workers in providing palliative care on patients living with chronic diseases we set the following objectives: To identify problems of patients with chronic diseases in CHUK, to sort-out challenges of anthropo-social workers in providing palliative care in CHUK, to highlight the role of anthropo-social workers in providing palliative care in CHUK.

\section{LITERATURE REVIEW}

In this research palliative care is the active, holistic care of people with chronic diseases involving management of pain and other symptoms and the provision of psychological, social and spiritual support.

\subsection{Anthropo-Social Work Role}

Anthropo-social workers' role focuses on responding to social, emotional and practical needs of the patient and family ${ }^{7}$.

\subsubsection{Psychosocial Support}

Psychosocial support consists in co-facilitation of family meetings, bereavement risk assessment and bereavement support.

\footnotetext{
${ }^{3}$ R. Moynihan, I. Heath, D. Henry, (2002). Selling sickness: the pharmaceutical industry and disease mongering, 886-891.

${ }^{4}$ Solomon Asaba. (2016). Rwanda: Palliative Care - Keeping Hope Alive for the Terminally Ill. In the The New Times, 10 October 2016.

${ }^{5}$ C. Ntizimira, (2013).The Spirit of Palliative Care" First impatient center for end of life care in Rwanda: in eHospice.

${ }^{6}$ Ministry of Health.(1999). Joint hypermobility and genetic collagen disorders: are they related? $188-191$.

${ }^{7}$ E. A. Strada, (2013).The helping professional's guide to end-of-life care. Oakland, CA: New Harbinger Publications, Inc.
} 


\subsubsection{Therapeutic Interventions}

This consists in developing and designing therapeutic interventions to suit patients and their families. Examples of such interventions include art, play, storytelling therapy, the compilation of memory boxes as well as reminiscence therapy and cognitive behavioral therapy.

\subsubsection{Psychosocial Assessments}

Anthropo-social workers assess clients and families and include comprehensive information to inform decision-makers and facilitate care planning and delivery. Assessment is an iterative process that is crucial to team functioning and decision-making. Each professional member of an inter-professional team brings important aspects to holistic assessments of clients and families ${ }^{8}$.

\subsubsection{Counseling}

Anthropo-social workers also provide emotional support, counseling, and psychotherapy to patients and their families who are experiencing psychological and emotional difficulties in the face of terminal and/or debilitating illness. Anthropo-social workers may employ a combination of clinical social work modalities to help their clients evaluate and manage their thoughts and emotions, as well as overcome various behavioral challenges.

\subsubsection{Advocacy}

Anthropo-social work profession is fundamentally committed to the promotion of social justice and social change. Therefore, anthropo-social worker advocates for the needs, decisions, and rights of clients and families in palliative and end of life care. Anthropo-social worker's advocacy addresses clinical and policy issues at micro, mezzo, and macro levels of the health care system and in the broader community.

\subsubsection{Care Delivery}

Care delivery is based on the assumption that the person living with terminal illness and his or her family is the unit of care, and that an interdisciplinary team, which includes social workers, best provides such care. Care delivery is regularly reviewed and adjusted according to changing care needs throughout the course of illness and into bereavement.

During these situations, anthropo-social workers provide immediate psychological support and counseling, while also completing care coordination services by informing the rest of a client's treatment team so that they can collaborate to effectively address the patient's distress.

\subsection{Challenges Faced by Anthropo-Social Workers Involved in Palliative Care}

Like in other hospitals, discontinuity of care and accepting the shift in goals from intensive treatment to palliative care was emotionally difficult for staff and family ${ }^{9}$. Anthropo-social workers who oversee the treatment of patients at the end of life often face obstacles to providing optimal care. Among these obstacles are inadequate preparation for facilitating difficult conversations, insufficient compensation for the relational aspects of end-of-life care work (as compared to invasive procedures), and personal discomfort with dying and death. These challenges should be considered alongside those faced by patients and families in the process of formulating improvements in palliative care ${ }^{10}$.

\subsubsection{Inadequate Training}

The management of palliative care and the process of engaging in difficult conversations are topics that are frequently neglected in anthropo-social work profession. The conventional pedagogic method of "see one, do one, teach one" applied in anthropo-social work profession is typically absent when related to end-of-life care. Many hospitals and health centers which have anthropo-social workers and caregivers responsible for eliciting a patient's treatment preferences at the end of life and for facilitating difficult conversations with families receive inadequate preparation for these tasks

\footnotetext{
${ }_{9}^{8}$ J. W. Worden, (2009). Grief counseling and grief therapy (4th ed.). New York, NY: Springer.

${ }^{9}$ S. Lutz, (2011).Politique en soins palliatifs de fin de vie. Québec, Canada : Gouvernement du Québec, 12.

${ }^{10} \mathrm{~S}$. Lutz, (2011).Politique en soins palliatifs de fin de vie. Québec, Canada : Gouvernement du Québec, 12.
} 
including training in palliative care, unprepared to teach palliative care to younger students ${ }^{11}$. These issues are particularly distressing when compared with similar studies conducted on anthropo-social work practice of invasive procedures.

Consequently, it is relevant to offer stronger preparatory programs for palliative care and encourage the recognition of death as part of the life cycle.

\subsubsection{Insufficient Compensation}

An issue that receives little formal attention among anthropo-social workers who care for patients with chronic diseases is the way they are compensated for their work. Anthropo-social workers and caregivers who care for patients with chronic diseases and their families are often driven by an altruistic need to ease suffering. However, for many, altruism eventually confronts financial realities ${ }^{12}$. It is reasonable to assume that continuing disparities in compensation between anthroposocial workers who spend much of their time talking to patients and families and those who spend much of their time performing procedures may lead to low performance and dissatisfaction. More research is needed to examine whether these disparities in compensation actually lead to lower satisfaction of patients or whether this system has detrimental effects on patient care.

\subsubsection{Personal Discomfort with Death}

Many anthropo-social workers feel uncomfortable when directly addressing issues related to the chronic diseases (particularly those concerning spiritual and emotional needs) faced by patients and families with chronic diseases. Attention to dying patients tends to focus on tangible questions directed toward an anthropo-social worker. Anthropo-social workers frequently feel uncomfortable confronting death because they relate to and identify with terminally ill patients and their families and resist doing so in the name of professionalism. Death also means the loss of the patient; this may be interpreted by medical caregivers as that they have somehow failed in their work ${ }^{13}$.

\subsection{Anthropo-Social Impact of Chronic Diseases}

Chronic diseases have the negative impact on anthropo-social economic development within the community ${ }^{14}$.

\subsubsection{Impact of Chronic Diseases on the Family}

When a member of the family suffers from chronic diseases, the family dynamic may drastically change. A chronic disease has a monumental impact not only on the development of the individual suffering from it, but also on their family members and their relationships. Indeed, chronic diseases change the family members' roles, responsibilities and boundaries. It disrupts their self-images and self-esteem. It results in uncertain and unpredictable futures. Furthermore, it triggers distressing emotions anxiety, depression, resentments, feelings of helplessness, as well as diseases-related factors such as permanent changes in physical appearance or bodily functioning ${ }^{15}$.

Chronic diseases affect household investment and consumption patterns. Households often sell their possessions to cover lost income and health-care costs. Economic deprivation should leads also to reduce access to the requirements of a healthy life, including affordable nutritious foods, adequate housing and health care, and a good social support network such as family, friends and community groups. Having a child with a chronic disease affects the parents in unique ways as well it has a negative impact on the relationship, including lack of time with the spouse, communication problems, higher divorce rates, increased relationship conflict and role strain, as well as decreased relationship satisfaction ${ }^{16}$.

\footnotetext{
${ }^{11}$ M. Grawitz (1979). Methods and tools in social sciences, $2^{\text {nd }}$ edition, Dallas, Yellow Print, 120.

${ }^{12}$ Moses and Kelton. (1971). Research Methodology, Illinois, Inc, Itasca, 67.

${ }^{13}$ Solomon Asaba. (2016). Rwanda: Palliative Care - Keeping Hope Alive for the Terminally Ill.

${ }^{14}$ Carr . (2001). Prenatal diagnosis for inherited deafness-what is the potential demand? J Genet Couns 1121131

${ }^{15}$ R. Bayer, R. L. Spitzer, (1982) Edited correspondence on the status of homosexuality in DSM-III. 32-52

${ }^{16}$ Carr. (2001). Prenatal diagnosis for inherited deafness-what is the potential demand? J Genet Couns 1121131
} 
The spouse or partner of a person with chronic diseases can be faced with dual challenges: 1) as the primary provider of support to the ill partner and 2) as a family member who needs support in coping with diseases related stresses he or she is experiencing. The spouse may feel trapped while trying to balance dependence and autonomy of the patient with his or her own needs. He or she may feel tired or emotionally drained by the long duration of the diseases or the extent of the caregiver workload. The spouse may struggle with feeling powerless when his or her partner is in pain, or by the pressure to be emotionally strong ${ }^{17}$.

According to Brennan ${ }^{18}$ chronic diseases can magnify developmental issues, increase the desire to be socially accepted, and cause children and adolescents with chronic diseases to spend significantly more time in isolation than their peers. Children with chronic diseases may miss school more often and experience difficulties with concentration and mental functioning due to certain medications and stress related to their diseases. Children may have a difficult time conceptualizing their disease because during Piaget's concrete operation stage, children believe that they do not have good health because they have chronic diseases. This view changes during adolescence ${ }^{19}$.

\subsubsection{Impacts of Chronic Diseases on Patients}

Chronic diseases have negative impact on patient's economic status and employment opportunities in the long term. Indirect costs include reduction in income owing to lost productivity from diseases or death, the cost of adult household members caring for those who are ill, reduction in future earnings by the selling of assets to cope with direct costs and unpredictable expenditures and lost opportunities for young members of the household who leave school in order to care for adults who are ill or to help the household economy ${ }^{20}$. In fact, negative emotions due to the psychological consequences experienced by patients with chronic diseases ${ }^{21}$ are very common.

\subsubsection{Impacts of Chronic Diseases on Community}

The chronic diseases are a significant burden and impact negatively on the ability to live well, especially when a chronic disease presents a visible functional impairment or limitation. Individuals living "with long-term health problems are at high risk for lessened and impaired social interactions and social isolation" 22 .

Impaired social interaction relates to the state in which participation in social exchanges occurs it is dysfunctional or ineffective because of discomfort in social situations, unsuccessful social behaviors, or dysfunctional communication patterns. Indeed, social relationships are frequently disrupted and usually desintergrated under the stress of chronic diseases and its management because chronic diseases often involve disfigurement, limitations in mobility, the need for additional rest, loss of control of somebody ${ }^{23}$.

\subsection{Holistic Care to Patients with Chronic Diseases}

Coping is seen as a dynamic and fluctuating process and people use a range of coping strategies, depending on the situation. It is important not to permanently place an individual into any one coping strategy as each individual's coping may change over time as follow ${ }^{24}$ :

\footnotetext{
${ }^{17}$ R. Bayer, R. L. Spitzer, (1982). Edited correspondence on the status of homosexuality in DSM-III. 32-52

18 F. Brennan, (2007).Palliative care as an international human right. Journal of Pain and Symptom Management, 494-499.

${ }^{19}$ Idem

${ }^{20}$ Carr. (2001).Prenatal diagnosis for inherited deafness-what is the potential demand? J Genet Couns 1121-131

${ }^{21}$ National Association of Social Workers.(2005). NASW standards for social work practice in health care settings. Retrieved June 15, 2008, from

http://www.socialworkers.org/practice/standards/NASWHealthCareStandards.pdf.

${ }^{22}$ N. Ayed, (2015). Just palliative care: Responding responsibly to the suffering of the poor. Journal of Pain and Symptom Management, 505-12.

${ }^{23}$ N. Ayed, (2015). Just palliative care: Responding responsibly to the suffering of the poor. Journal of Pain and Symptom Management,505-12.

${ }^{24}$ S. J. Stern, K. S. Arnos, L. Murrelle, K. O. Welch, W. E. Nance, A. Pandya, (2002).Attitudes of deaf and hard of hearing subjects towards genetic testing and prenatal diagnosis of hearing loss. J Med Genet 39: 449-453
}

International Journal of Research in Sociology and Anthropology (IJRSA) $\quad$ Page | 19 


\subsubsection{Physical Care}

There are ways to make a person who is dying more comfortable. Discomfort can come from a variety of problems. For each, there are things you or a healthcare provider can do, depending on the cause. For example, a dying person can be uncomfortable because of: pain, breathing problems, skin irritation, digestive problems, temperature sensitivity and fatigue ${ }^{25}$.

Pain killer (morphine) is an opiate, a strong drug used to treat serious pain. Sometimes, morphine is also given to ease the feeling of shortage of breath. Pain medication can make people confused or drowsy. You might have heard that giving morphine leads to a quicker death. Is that true? Most experts think this is unlikely, especially if increasing the dose is done carefully. Successfully reducing pain and/or concerns about breathing can provide needed comfort to someone who is close to dying ${ }^{26}$.

\subsubsection{Psychosocial Care}

Coping with a life-threatening disease and possibly debilitating symptoms, people living with HIV must often manage changing family dynamics, stigma in the community, diseases of other family members, loss of their own physical functions, loss of income, depression, and hopelessness. Even in communities that have actively campaigned to prevent HIV/AIDS discrimination, people with HIV and their families experience stigma. In this context, psychosocial support can significantly improve their quality of life ${ }^{27}$.

\subsubsection{Social Care}

People who are aware that their lives have been shortened by life limiting diagnoses face enormous alterations and challenges to many aspects of their lives. Professional family and community-based support can make a difference to the quality of people's lives and an opportunity for people to remain in their homes and minimize institutional admissions to hospital, hospice or nursing homes. However, anthropo-social support is conceptualized as instrumental support including both financial support and assistance with tasks, emotional / appraisal support, information, companionship, and self-esteem support $^{28}$.

\subsubsection{Spiritual Care}

Patients who need a spiritual support may utilize their beliefs in coping with diseases, pain, and life stresses. Some studies indicate that those who practice the spirituality from their religions tend to have a more positive outlook and a better quality of life ${ }^{29}$.

Attending to spiritual needs is another key component of palliative care. Some programs have pastoral counselors on staff, while others collaborate with faith-based community organizations to assure spiritual support for their patients. This type of assistance can help HIV-positive persons and their families prepare for death when it becomes inevitable, assist with funeral and burial plans, and provide ongoing comfort to the bereaved family. Psychosocial and spiritual supports are often inextricably united, especially in communities with a strong faith tradition ${ }^{30}$.

\section{Materials AND Methods}

To conduct this research, descriptive and analytical methods were combined whereby both quantitative and qualitative approaches have been used. This research to be successful different techniques have been used. As techniques, we used the interview, questionnaire, observation and documentary.

\footnotetext{
${ }^{25}$ A.G. Lipman, (2005). Pain as a human right: The 2004 Global Day Against Pain. Journal of Pain and Palliative Care.Pharmacotherapy, 85-100.

${ }^{26}$ A.G. Lipman, (2005). Pain as a human right: The 2004 Global Day Against Pain. Journal of Pain and Palliative Care.Pharmacotherapy, 85-100.

${ }^{27}$ S. J. Stern, K. S. Arnos, L. Murrelle, K. O. Welch, W. E. Nance, A. Pandya. (2002). Attitudes of deaf and hard of hearing subjects towards genetic testing and prenatal diagnosis of hearing loss. J Med Genet 39: 449453.

${ }^{28}$ C. Sepulveda et al. (2002). Palliative Care; The World Health Organization's Global Perspective. Journal of Pain and Symptom Management. 24, 91-96.

${ }^{29}$ Idem.

${ }^{30}$ C. Sepulveda, et al. (2003). Quality care at the end of life in Africa. BMJ. 327: 209-213.
} 
The research population of our study was composed of the hospitalized in-patients of CHUK. The number of hospitalized patients was 21,829 and the total population of our research was 228 patients living with chronic diseases. According to Grinnell and William, the population is defined as the set of elementary units on which the analysis is carried out ${ }^{31}$.

The target population is the total group of individuals from which the sample might be drawn. A sample is the group of people who take part in the investigation. In our research we took a sample of 228 patients with chronic diseases among 21829 total population.

\subsection{Sampling Procedure and Techniques}

According to Deldome and Demoulin ${ }^{32}$, a sample is a part of the target (or accessible) population that was procedurally selected to represent it. According to A. Bouchard when the universe of a survey is inferior or equal to 10,000 of individuals that correspond to the sample of 96 within a marginal errors of $10 \%$ and a precision of $95 \%$ times out of 100 as stated below:

Given N=the height of finished universe

$\mathrm{n}=$ the height of sampling for the finished universe 96

$\mathrm{nc}=$ The corrected sampling

Note that 68 is a number which represents the height of a sample for finished universe. As we work at the finished universe, the formula is applicable to our study as developed below ${ }^{33}$ :

$$
\begin{aligned}
& n c=\frac{N \times n}{N+n} \\
& n c=\frac{228 \times 96}{228+96}=67.5 \cong 68
\end{aligned}
$$

The 68 equals to the sample of our study that represented our respondents.

\subsection{Methods}

In our research we used analytical and descriptive method.

Selection criteria of respondents

- Respondents had to be be at least 25 years old

- Respondents had to be be a hospitalized patients

- Respondents had to be be hospitalized in CHUK at least four weeks ago

Those who met the criteria above were selected to participate in this study through questionnaire and focus group discussion.

\subsection{Research Techniques and Methods}

Referring to Willis Y.O. and David $\mathrm{O}^{34}$, instrument refers to the tools to be used for data collection and how those tools will be developed. The most popular instruments for data collection that we used to collect data were questionnaires, interview, observation and documentation.

Following are the descriptions of each of those instruments or techniques we used.

Interview, a procedure of scientific investigation using a verbal communication ${ }^{35}$ has been used to selected five key informants including one (1) head of service, two (2) health providers and two (2) patients.

\footnotetext{
${ }^{31}$ Grinnell Williams, (1990). Research in social work, Illinois, A premier, F.E Peacock Publishers, 118.

${ }^{32}$ Deldome and Demoulin, (1994). Introduction to Social Work Research, New York, Library of Congress, p 9498.

${ }^{33}$ A. Bouchard (1992). Applied statistics to Geography. Legonette, Paris, 47.

${ }^{34}$ Y.O. Willis, David. ( 2008). A Social research, New York, Russell Sage Foundation, 95.
} 
Questionnaire, an easy tool of data collection within which the researcher uses short, clear and understandable listed questions to know what a research participant thinks about $\mathrm{it}^{36}$, was used distributing questionnaires to 68 hospitalized patients of CHUK; and this was in the purpose of verifying whether our research hypotheses stated in introduction of our research can be rejected or maintained. The ages of respondents range between 25 years old to 65 years old and above. The respondents were met at CHUK at the morning during staff meeting headed by director of CHUK.

The technique of observation involved observing an individual behavior and studied their anthroposocial phenomena ${ }^{37}$. According to Connor $\mathrm{S}^{38}$ observation is the most important technique used by researcher to collect data. Nothing can replace a researchers' direct contact with his/her domain and no other technique can enable a researcher in gathering more ideas than observation technique". During the period of observation the information gathered were hold at CHUK in the period of visiting patients at the end of every weekend. This technique helped us in gathering information that we are sure is a hundred percent reliable because this study needed to be at the field and the researcher to observe the reality by asking questions through direct contact with respondents.

The documentary technique was also used in analysis of documents. In the line with this technique, Grahame $\mathrm{R}^{39}$, says that a document refers to any written material that may be used as a source of information about the subject matter. He further explains that although written materials are involved in the experiments, survey, and observation studies at one stage or other. Attention was focused on those materials and the recording of which was the result of any specials efforts on the part of investigator.

We consulted different written sources including books, CHUK reports, and internet regarding the role of anthropo-social workers in providing palliative care to the patient with chronic diseases.

Analytical method was used when analyzing the data obtained from the field of study through the questionnaire, interview, observation and documentation. According to Grawitz ${ }^{40}$, the analytical method helps to analyze data and information collected in order to draw what was referred to as assumptions.

During the research, the descriptive method helped us to describe, interpret and qualify results from the field in order to give them interpretations and accurate explanations. Descriptive research is used to describe characteristics of a population or phenomenon being studied. The description is used for frequencies, averages and other statistical calculations. Qualitative research often has the aim of description and researchers may follow-up with examinations of why the observations exist and what the implications of the findings are ${ }^{41}$.

\section{Presentation And Discussion Of Findings}

The study involved a sample population of 68 respondents who provided us with details on the role of anthropo-social workers in providing palliative care to patients living with chronic diseases.

\subsection{Identification of Respondents}

$41 \%$ (28 people) of respondents are male and 59\% (40) are female. So the great proportion of the respondents are female. This proportion shows us that most female are affected and infected with chronic diseases as they represent more than the half of the entire chosen sample population. This shows that the big number of chronic diseases affects women in this research conducted at CHUK.

\footnotetext{
${ }^{35} \mathrm{R}$. Day, 1996. How to write and publish a scientific paper, $4^{\text {th }}$ edition, Cambridge, Cambridge university press, 38. Carr. (2001). Prenatal diagnosis for inherited deafness-what is the potential demand? J Genet Couns 1121-131.

${ }^{36}$ Deldome and Demoulin. (1994). Op. Cit., 57.

${ }^{37}$ Carr, (2001). Prenatal diagnosis for inherited deafness-what is the potential demand? J Genet Couns 1121-131.

${ }^{38}$ S. Connor, (2003). New Initiatives Transforming Hospice Care. hospice Journal - Physical, Psychosocial, \& Pastoral care of the dying.193-203.

${ }^{39} \mathrm{R}$. Grahame, (1992). A proposed set of diagnostic criteria for the benign joint hyper mobility syndrome.31: 205.

${ }^{40}$ S. Cameron, K. Defilippi, (2007).Promoting the integration of Quality Palliative Care .The South African Mentorship Program. Journal of Pain and Symptom Management, 552-557.

${ }^{41}$ S. Lutz, (2011). Politique en soins palliatifs de fin de vie. Québec, Canada : Gouvernement du Québec, 24.
} 
The factor age helps to determine the age strata more concerned with chronic diseases. $14.7 \%$ of the respondents are aged of 25-30 years. 25.0\% are aged of 31-35 years old. As for $27.9 \%$ of the respondents, they are aged of 36- 40,13.2\% of the respondents are aged between $41-45,8.8 \%$ with 46-50 years old and finally those who are aged more than 50 years old are $10.3 \%$. Finally, the age allows us to determine who are most affected and infected with chronic diseases.

The analysis shows that respondents of 36-40 years old participated in this research at a high consideration, while whose ages ranged between 40 and 50 and above are less represented due to the fact that many of them affected with chronic diseases could not respond clearly to the questionnaire.

The occupation of the respondents helps us to determine the category which is most found on our research area. Our findings show that $6 \%$ are students; $7 \%$ are unemployed; $57 \%$ are farmers and $24 \%$ have worked in the private sector; $9 \%$ are employed by the public sector, whereas $3 \%$ are retired. A great number of patients hospitalized with chronic diseases had agricultural activities.

The marital status of the respondents helps us to determine who face most chronic diseaes in the society. The findings illustrate that $71 \%$ of the respondents are married; $12 \%$ are single and $9 \%$ are widows or widowers. Divorced are represented by $6 \%$ while separated are represented by $3 \%$.Therefore the research show that married people are vulnerable from chronic diseases.

The instruction level of respondents is very important in verifying the reliability of the responses given by the population. The findings attest that $35 \%$ of the respondents have primary education; $51 \%$ secondary education, and $13 \%$ studied at university.

This shows that victims of chronic diseases are encountered in all the strata of people who have lower education. The great proportion of the chosen sample is those who have secondary education level, follows those with primary education.

\subsection{Chronic Diseases Infected Patients at CHUK}

According to the respondents chronic diseases are big problems to patients at CHUK where the big number of hospitalized clients are affected and infected with chronic diseases.

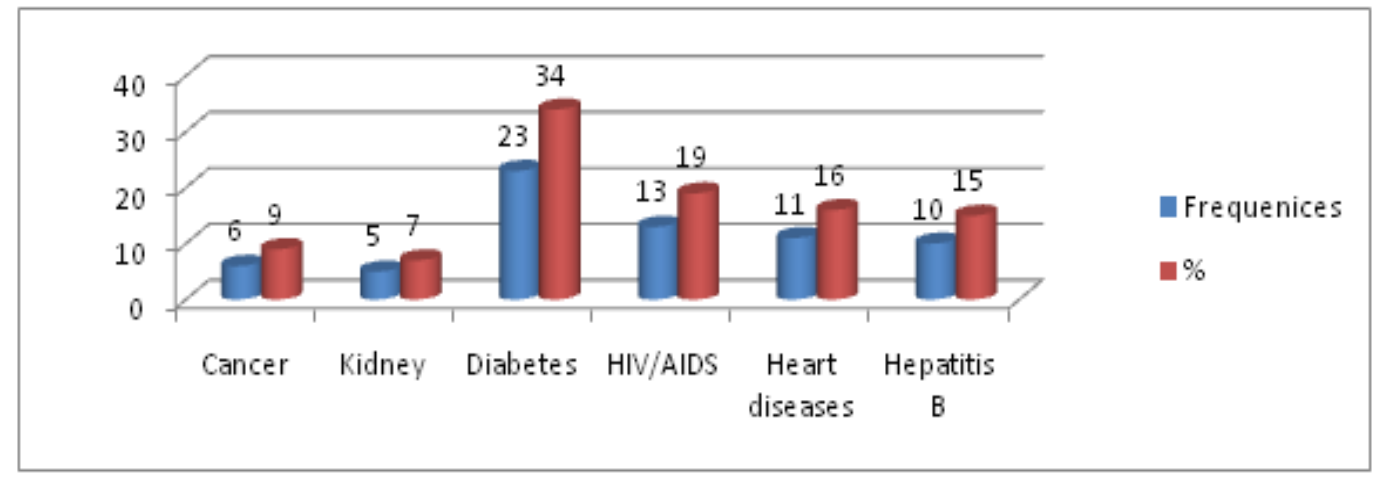

Graph1. Chronic diseases infected patients at CHUK

Source: Primary data, October 2017

As illustrated by this graph, $34 \%$ of the respondents are affected with diabetes, $19 \%$ with HIV/AIDS, $16 \%$ with heart diseases, $15 \%$ of the respondents suffer from hepatitis B, $7 \%$ and $9 \%$ are infected with kidney and cancer.

The analysis of this graph shows the high level of frequencies of diabetes, HIV/AIDS and heart diseases.

\subsection{Problems of Patients with Chronic Diseases at CHUK}

Opinions of our respondents about the problems they faced show us how we could categorize them according to their level of suffering especially patients hospitalized at CHUK living with chronic diseases.

In presenting data, the indicator of emotional problems is crucial for this research because it certainly allows us to determine which categories of problems impact the patients with chronic diseases 


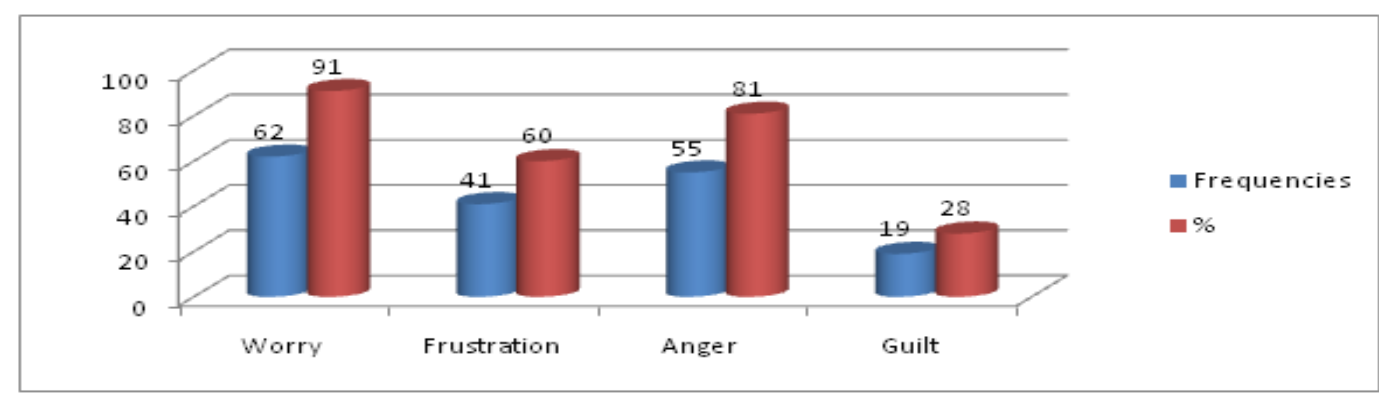

Graph2. Emotional problems of patients with chronic diseases at CHUK

Source: Primary data, October 2017

Statistics from the above graph show that according to the impacts of emotional problems of patients with chronic diseases, $81 \%$ among them show anger, $91 \%$ show worry, $60 \%$ show frustration while $28 \%$ confirm guilt rooted in their past.

Consequently, a great proportion of our respondents confirm worry and anger as the results of emotional problems.

\subsection{Psychological Problems of Patients with Chronic Diseases at CHUK}

Psychological problems have their manifestations through body gestures of patients with chronic diseases; here we are presenting how psychological problems caused the negative impacts on patients due to chronic diseases.

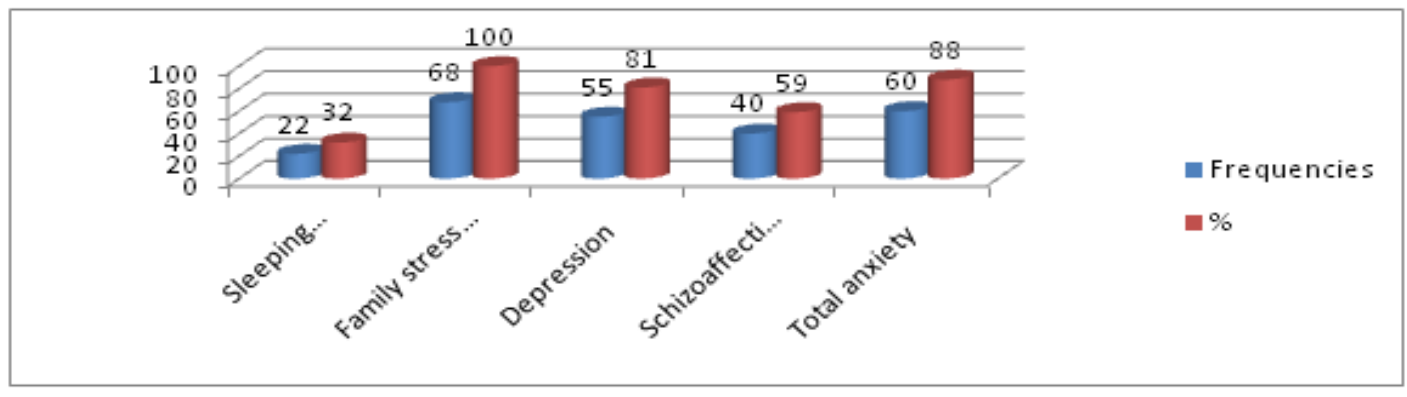

Graph3. Psychological problems of patients with chronic diseases at CHUK

Source: Primary data, November 2017

Considering the statistics illustrated in this graph, $100 \%$ reported family tension and stress; $78 \%$ reported total anxiety; $81 \%$ depression; $59 \%$ of respondents agreed on schizoaffective disorder; while $32 \%$ reported sleeping disorder due to chronic diseases.

According to the information provided by interviewees, particularly the head of services and health providers of CHUK, they emphasized the frequent family stress, depression and tension and total anxiety.

Analytically, this testifies that family stress and tension, total anxiety and depression within the family are the big issue; the family spends all time in caring about the person with chronic diseases.

\subsection{Economic Problems of Patients with Chronic Diseases at CHUK}

The following graph presents the economic problems of the patients with chronic diseases at CHUK and indicates the frequency at which they have been reported by our respondents.

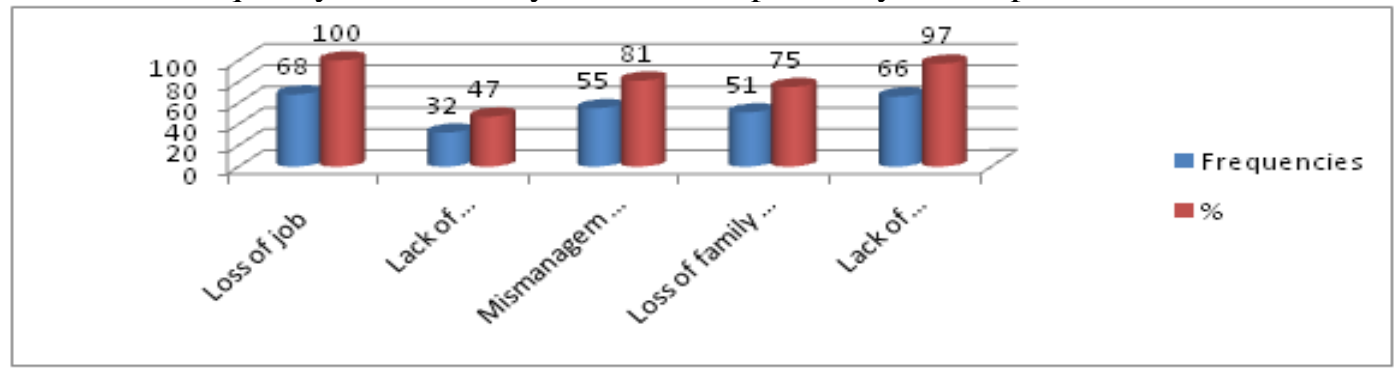

Graph4. Economic problems of patients with chronic diseases at CHUK

Source: Primary data, May 2018 
As it is illustrated by the graph above, concerning economic problems of patients with chronic diseases; $100 \%$ of respondents reported the loss of job; $97 \%$ reported the lack of money for treatment; while $81 \%$ of the respondents reported the mismanagement of properties. The lack of support from friends and families is another issue due to economic problems of the patients with chronic diseases where the respondents show $47 \%$ while $75 \%$ of the respondent shows loss of family income.

Analytically, the loss of job, the lack of money for treatment and the mismanagement of properties in the family which has a person with chronic disease as stated by hospitalized patients in CHUK bring a negative impact on the patients with chronic disease due to the economic problems especially in the family of diseased person.

During the interview, the head of services and health provider's executive secretary showed how loss of job, lack of money for treatment and mismanagement of properties affected the whole family in which the patient with chronic diseases live. They said that the loss of job is a big issue which led the family in extreme poverty.

\subsection{Anthropo-Social Problems of Patients with Chronic Diseases at CHUK}

The graph below presents our findings about the social life problem of patients with chronic diseases and their impacts.

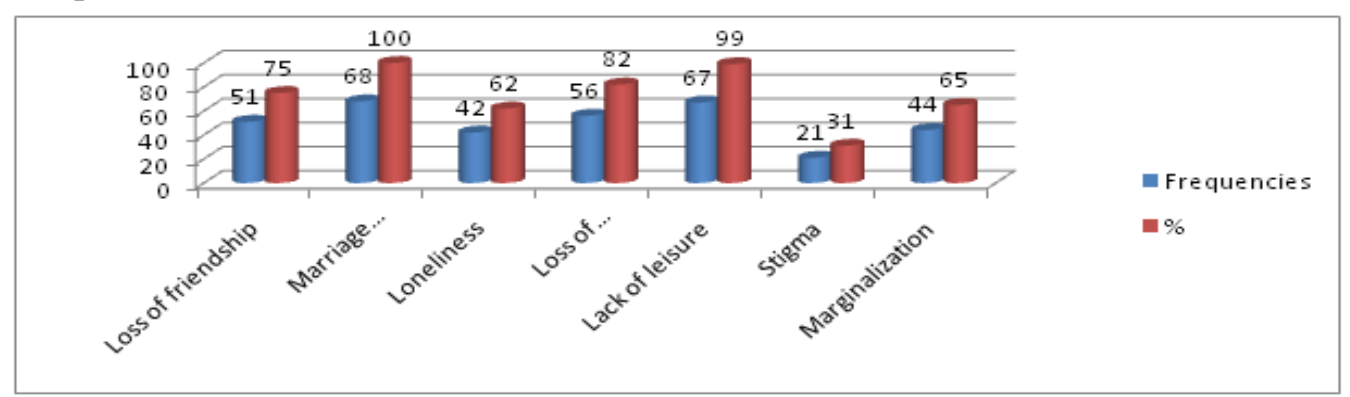

Graph5. Anthropo-social problems of patients with chronic diseases at CHUK

Source: Primary data, November 2017

As shown by the graph above, $100 \%$ reported marriage breakdown; $99 \%$ reported lack of leisure; $82 \%$ of respondents reported loss of relationship; 75\% showed loss of friendship; 65\% of the respondents confirm marginalization; while $31 \%$ of respondents reported stigma as the impacts of anthropo-social problems to the patients with chronic diseases at CHUK.

The interview revealed that some of social problems and their impacts to the patients with chronic disease are marriage breakdown, lack of leisure and loss of relationship among them and within the family as stated by the head of services and health providers in CHUK.

\subsection{Challenges Faced by Palliative Care in Anthropo-Social Work Profession}

To make a fine research about the role of antropo-social workers in providing palliative care to patients with chronic diseases at CHUK, after analyzing their problems we have to analyze some challenges they have.

\subsubsection{Challenges to the Delivery of Palliative Care to Patients with Chronic Diseases at CHUK}

Through questionnaire and interview, our research strives to know some challenges to the delivery of palliative care to patients with chronic diseases at CHUK.

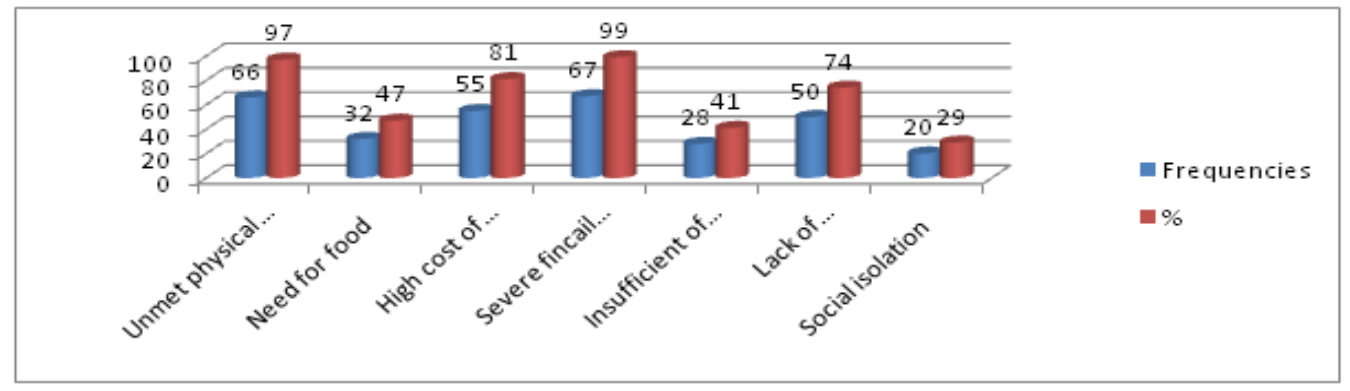

Graph6.Challenges to the delivery of palliative care to patients with chronic diseases at CHUK

Source: Primary data, November 2017 
The findings highlighted in the graph above illustrate different challenges to the delivery of palliative care to patients with chronic diseases at CHUK. The majority of respondents representing $99 \%$ of all respondents fall in the category of severe financial constraints; and $97 \%$ of respondents showed unmet physical needs, $81 \%$ with high cost of drugs; $74 \%$ demonstrated lack of psychological support; $41 \%$ of respondents showed insuffiency of caregivers; while $29 \%$ reported social isolation.

It is the same that after data analysis from interview, the head of services and health providers at CHUK confirmed severe financial constraints, unmet physical needs and high cost of drugs.

Therefore, to deliver palliative care needs some specific intervention in order to help in time patients who suffer from chronic diseases.

\subsubsection{Challenges Faced by Anthropo-Social Workers Involved in Palliative Care}

Challenges faced by anthropo-social workers in helping patients with chronic diseases to cope with their problems were considered as an important variable in a research study like this. The results are shown in the graph below.

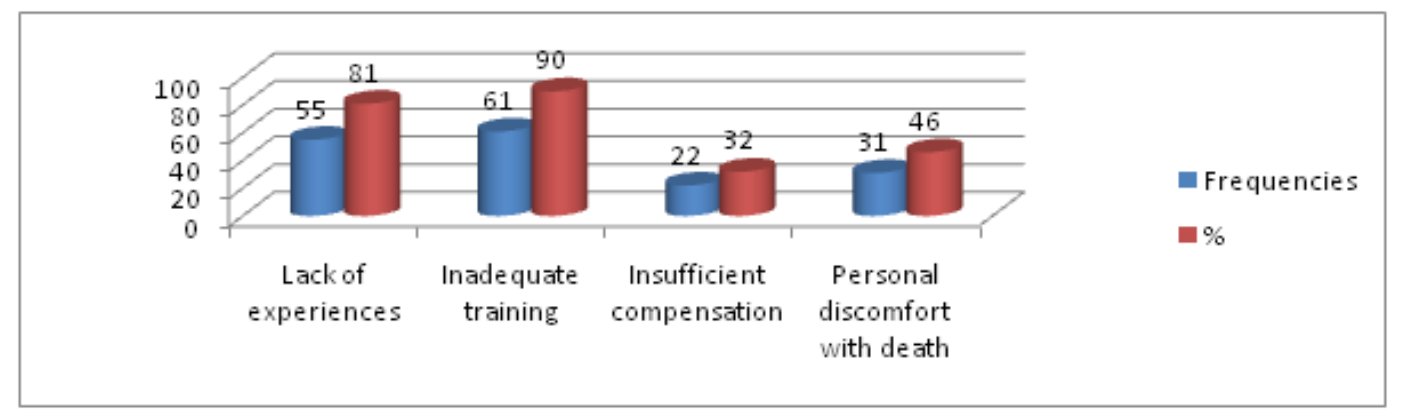

Graph7. Challenges faced by Social workers involved in palliative care

Source: Primary data, November 2017

The graph above is illustrating the challenges faced by anthropo-social workers involved in palliative care. The findings show that $90 \%$ of respondents have inadequate training; $81 \%$ lack experiences; $46 \%$ confirmed personal discomfort with death while $32 \%$ showed insufficient compensation.

According to the analysis made after questionnaire and interview from the head of services and health providers at CHUK the facts show that the lack of experience and inadequate training are barriers of anthropo-social workers to deliver correctly and professionally palliative care to patients with chronic diseases.

\subsubsection{Challenges Faced by Patients with Chronic Diseases}

To be sure of challenges of patients with chronic diseases at CHUK, we got an idea to ask whether respondents have at least experienced or had proof of any case of challenges during their painful life. Here below are their answers.

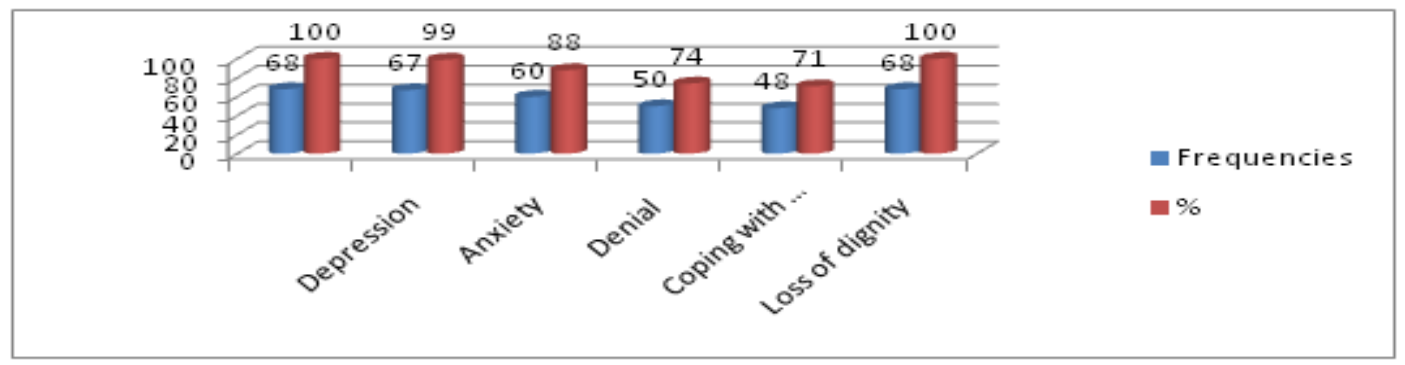

Graph8. Challenges faced by patients with chronic diseases

Source: Primary data, May 2018

As it is shown by the above graph; $100 \%$ of all respondents had loss of dignity and pain management; 99\% showed the problem of depression and $88 \%$ demonstrated anxiety; $74 \%$ of the respondents were with denial while $71 \%$ demonstrated difficulties in coping themselves with their problems caused by chronic diseases. 
The head of services and health providers have also confirmed the loss of dignity and problems of pain management. This explains that the loss of dignity and problems of pain management constitute a big issue in diminishing the hope of surviving to the patients with chronic diseases at CHUK.

\section{CONCLUSION}

Research participants have attested, 100\% confirmed psychosocial, advocacy and care delivery as the role of anthropo-social workers in providing palliative care at CHUK. To enhance anthropo-social work of palliative care, therapeutic intervention and counseling, must be taken into consideration. According to the findings, the fact shows that the high frequency of the respondents confirms economic, daily life and social problems.

To improve anthropo-social wellbeing of patients at CHUK, challenges on the side of anthropo-social workers and on the side of patients as mentioned above must be removed or reduced. According to the findings $67 \%$ of respondents experience challenges to the delivery of palliative care to patients with chronic diseases at CHUK; $62.2 \%$ of respondents demonstrated challenges faced by anthropo-social workers involved in palliative care; while $88.6 \%$ of respondents showed challenges faced by patients with chronic diseases at CHUK.

To sum up we confirm that the biggest challenge was the lack of professional palliative care through verbal and non verbal communication between patients in critical state and interveners the reason why not only palliative care of anthropo-social workers and health providers must be improved but also different stakeholders should intervene in the wellbeing of patients living with chronic diseases. We support that anthropo-social workers' role is crucial intervention to the chronic diseases of hospitalized patients at CHUK and their skills must be improved.

\section{REFERENCES}

[1] Ayed N., (2015): Just palliative care: Responding responsibly to the suffering of the poor: Journal of Pain and Symptom Management, 505-12.

[2] Bayer R., Spitzer R. L., (1982): Edited correspondence on the status of homosexuality in DSM-III.

[3] Bouchard A., (1992): Applied statistics to Geography. Legonette, Paris.

[4] Brennan F., (2007): Palliative care as an international human right. Journal of Pain and Symptom Management, 494-499.

[5] Cameron S., \& Defilippi K., (2007): Promoting the integration of Quality Palliative Care. The South African Mentorship Program: Journal of Pain and Symptom Management, 552-557.

[6] Carr, (2001): Prenatal diagnosis for inherited deafness-what is the potential demand? J. Genet Couns.

[7] Connor S., (2003): New Initiatives Transforming Hospice Care. Hospice Journal - Physical, Psychosocial, \& Pastoral care of the dying, 193-203.

[8] Daley A., Matthews C., Williams A., (2006): Heart Failure and Palliative Care Services Working in Partnership: Report of a New Model of Care, Palliative Medicine.

[9] Day R., 1996: How to write and publish a scientific paper, $4^{\text {th }}$ edition, Cambridge, Cambridge university press.

[10] Deldome, Demoulin, (1994): Introduction to Social Work Research, New York, Library of Congress.

[11] Grawitz M., (1979): Methods and tools in social sciences, $2^{\text {nd }}$ edition, Dallas, Yellow Print.

[12] Grinnell W., (1990): Research in social work, Illinois, A premier, F.E Peacock Publishers.

[13] Human Resources for Health Strategic Plan 2011-2016, Ministry of Health Rwanda, Editor.

[14] Lipman A.G., (2005): Pain as a human right: The 2004 Global Day against Pain: Journal of Pain and Palliative Care. Pharmacotherapy, 85-100.

[15] Lutz S., (2011) : Politique en soins palliatifs de fin de vie. Québec, Canada : Gouvernement du Québec.

[16] Moses, Kelton, (1971): Research Methodology, Illinois, Inc, Itasca.

[17] National Association of Social Workers, (2005): NASW standards for social work practice in health care settings. Retrieved June 15, 2008: http://www.socialworkers.org/practice/standards/NASWHealthCare Standards.pdf.

[18] Sepulveda C., et al. (2002): Palliative Care; The World Health Organization's Global Perspective: Journal of Pain and Symptom Management. 24, 91-96.

[19] Sepulveda C., et al. (2003): Quality care at the end of life in Africa. BMJ.

[20] Smith J. A, Greer T., Sheets T., Watson S., (2011): Is there more to yoga than exercise? Alternative Therapy Health Medicine, 17 (3), 22-29. 
[21] Solomon Asaba, (2016): Rwanda: Palliative Care - Keeping Hope Alive for the Terminally Ill: The New Times, 10 October 2016.

[22] Stern S. J., Arnos K. S., Murrelle L., Welch K. O., Nance W. E., Pandya A., (2002): Attitudes of deaf and hard of hearing subjects towards genetic testing and prenatal diagnosis of hearing loss, J Med Genet.

[23] Strada E. A., (2013): The helping professional's guide to end-of-life care. Oakland, CA: New Harbinger Publications, Inc.

[24] Willis Y.O., David, (2008): A Social research, New York, Russell Sage Foundation.

[25] Worden J. W., (2009): Grief counseling and grief therapy (4th ed.). New York, NY: Springer.

Citation: Father Dr. Lucien HAKIZIMANA et.al. "Anthropo-Social Palliative Care to Dying Patients with Chronic Diseases: A Case Study of Centre Hospitalier Universitaire de Kigali (CHUK): 2015-2017" International Journal of Research in Sociology and Anthropology (IJRSA), vol 4, no. 3, 2018, pp. 15-28. doi:http://dx.doi.org/10.20431/2454-8677.0403002.

Copyright: (c) 2018 Authors. This is an open-access article distributed under the terms of the Creative Commons Attribution License, which permits unrestricted use, distribution, and reproduction in any medium, provided the original author and source are credited. 